\title{
Aerothermal databases and load predictions for Retro Propulsion-Assisted Launch Vehicles (RETALT)
}

\author{
Mariasole Laureti $^{1}$ (D) Sebastian Karl ${ }^{1}$
}

Received: 27 July 2021 / Revised: 24 November 2021 / Accepted: 13 December 2021 / Published online: 4 January 2022

(c) The Author(s) 2022

\begin{abstract}
The assessment of thermal loads occurring on reusable launch vehicles during the entire trajectory is essential for the correct dimensioning of the thermal protection system. Due to the costs and limitations of ground-based testing for largescale vehicles, these predictions rely intensively on numerical simulations (CFD). The need of aero-thermal databases, as a fast-response surrogate model for the aero-thermodynamic heating, arises from the practical impossibility of performing unsteady CFD analysis over the entire trajectory due to the large disparity of fluid mechanical and structural time scales. The construction of these databases is based on a representative set of CFD simulations which cover, at a minimum, the flight regimes with significant thermal loads. The aim of this paper is to analyse the results of these representative CFD simulations during both the ascent flight and atmospheric entry for the RETALT1 vehicle to show typical flow field phenomena occurring during these phases and the resulting heating patterns.
\end{abstract}

Keywords Reusable launch vehicle $\cdot$ Retro-propulsion $\cdot$ Aerothermal loads $\cdot$ CFD $\cdot$ RANS

$\begin{array}{ll}\text { Acronyms } \\ \text { ACS } & \text { Aerodynamic Control Surfaces } \\ \text { ATDB } & \text { Aero-Thermal Data Base } \\ \text { CFD } & \text { Computational Fluid Dynamic } \\ \text { GTO } & \text { Geostationary Transfer Orbit } \\ \text { LEO } & \text { Low Earth Orbit } \\ \text { MECO } & \text { Main Engine Cut Off } \\ \text { RLV } & \text { Reusable Launch Vehicle } \\ \text { SSTO } & \text { Single Stage To Orbit } \\ \text { TPS } & \text { Thermal protection system } \\ \text { TSTO } & \text { Two Stage To Orbit } \\ \text { VTVL } & \text { Vertical Take-off Vertical Landing }\end{array}$

\section{Symbols}

Kn $\quad$ Knudsen number

$M \quad$ Mach number

$q \quad$ Heat flux per unit area $\left(k W / \mathrm{m}^{2}\right)$

$\rho \quad$ density $\left(\mathrm{kg} / \mathrm{m}^{3}\right)$

$T \quad$ Temperature $(K)$

Mariasole Laureti

mariasole.laureti@dlr.de

Sebastian Karl

sebastian.karl@dlr.de

1 Deutsches Zentrum für Luft und Raumfahrt (DLR), Institute of Aerodynamics and Flow Technology, Bunsenstraße 10,

37073 Göttingen, NS, Germany

\author{
$T_{w} \quad$ Wall temperature $(K)$ \\ $u \quad$ Velocity component along the launcher longitu- \\ dinal axis $(\mathrm{m} / \mathrm{s})$
}

\section{Introduction}

Over the last 10-15 years, partial or complete reusable launch systems have received increasing interest [9] because of their potential to significantly reduce recurrent launch costs and lower the environmental impact.

In the framework of its Reusable Launch Vehicle (RLV) activities, US-American companies SpaceX and Blue Origin promoted several studies and technology developments focused on advancing the maturity level of reusable launchers. The SpaceX Falcon 9 rocket represents a successful example of a Vertical Takeoff Vertical Landing (VTVL) Two Stage To Orbit (TSTO) RLV.

In Europe, few researches have been performed on this concept, and limited knowledge and know-how is available. RETALT is one of the European projects that aims at investigating the launch system reusability technology of VTVL RLVs, applying retro-propulsion combined with aerodynamic control surfaces [11]. Two reference launch vehicle configurations are defined: 
- RETALT1: A configuration similar to the SpaceX rocket "Falcon 9" that will be the reference for a state- of-the-art TSTO RLV

- RETALT2: A configuration similar to the DC-X that will serve as a reference for a VTVL SSTO.

The layout and system analysis of reusable launch vehicles include major challenges related to the application of a robust, light-weight, inexpensive and serviceable Thermal Protection System (TPS). The correct sizing of such a system, as well as other important structural parts like the Aerodynamic Control Surfaces (ACS), relies on an accurate evaluation of thermal loads occurring during the entire atmospheric flight path. Since extensive experimental campaigns of large-scale vehicles are extremely expensive and subjective to several limitations, these predictions are mainly performed by numerical simulations (CFD). Such CFDbased load predictions need to be coupled with an analysis of the structural response using a heating model.

The large disparity of fluid mechanical and structural time scales makes unsteady CFD analysis over the entire trajectory practically impossible, leading to the necessity to develop fast-response surrogate models for the aero-thermodynamic heating. This need has been fulfilled through the creation of an aero-thermal database (ATDB) which represents a surrogate aero-thermodynamic heating model consisting of a set of steady-state CFD results for the surface heat fluxes. The CFD simulations are performed at different trajectory points, operational conditions of the engines and different surface temperatures. The use of interpolation algorithms allows to estimate the local heating rate on each point of the vehicle surface as a function of flight time and local surface temperature. Such surrogate model for the aerothermal loads can be easily coupled to a structural response model to evaluate the temperature history in each location on the vehicle surface during the entire atmospheric flight.

The aero-thermal database created for the RETALT1 vehicle is based on a computational matrix that covers the entire flight trajectory.

This paper is focused on the analysis of representative flow field solutions, provided by the extensive CFD campaign performed for the ATDB construction. This allows the analysis of typical phenomena occurring during both the ascent flight and the atmospheric entry, i.e. plume interaction, immersion of the vehicle in hot exhaust gases, vehicle aerodynamics, and the resulting heating patterns. In this regard, it is interesting to highlight the presence of hot spots due to the plume interaction and to observe at which flow field conditions the heat flux peak on the aerodynamic surfaces and protrusions occur.

Furthermore, a turbulence modelling sensitivity analysis has been carried out in order to observe the effects on the external flow field structure and provide an uncertainty assessment on the thermal loads occurring on the launcher surface.

\section{Mathematical and numerical model}

The construction of aerothermal databases requires detailed heat flux data for different flight regimes and surface temperatures. To obtain the necessary data, CFD simulations were carried out at a representative set of flow conditions which cover the entire atmospheric flight regime.

These CFD analyses are performed with the hybrid structured-unstructured DLR Navier-Stokes solver TAU [10]. The TAU code is a second-order finite-volume flow solver for the Euler and Navier-Stokes equations in their integral forms, using eddy viscosity, Reynolds stress or detached and large eddy simulation for turbulence modelling.

For the present investigation, the Spalart-Allmaras oneequation eddy viscosity model [13] has been employed. The choice of this turbulence model was motivated by its ability to reproduce the structure of engine exhaust-plumes during retro-propulsion maneuvers [4] and by the general applicability for heat flux predictions in a wide range of hypersonic and reacting flow regimes [5, 8].

The AUSMDV flux-vector splitting scheme was applied together with MUSCL gradient reconstruction to achieve second-order spatial accuracy whilst maintaining a robust numerical treatment of strong discontinuities.

The thermodynamic modelling is based on a mixture of thermally perfect gases. The properties of the individual species are either computed from spectroscopic constants using partition functions that include an accurate representation of high temperature effects, such as inharmonic corrections and coupling of rotational and vibrational degrees of freedoms for molecules [2], or from NASA Polynomials [7]. Appropriate mixture rules are applied to compute the thermodynamic properties depending on the local gas composition, pressure and density.

For the simulation of the RETALT1 vehicle, a chemically frozen mixture of air ( $76 \% \mathrm{~N}_{2}$ and $24 \% \mathrm{O}_{2}$ by mass fraction) and engine exhaust gas $\left(97.7 \% \mathrm{H}_{2} \mathrm{O}, 2 \% \mathrm{H}_{2}, 0.2 \% \mathrm{OH}\right.$ and tracer species) is considered. The additional heat release due to post-combustion of the fuel-rich exhaust gases in the flow field around the rocket configuration is neglected.

This is justified by a preparatory investigation of a representative simplified axis-symmetric retro-propulsion configuration. The results are summarized in Figs. 1 and 2. The free stream conditions correspond to a flight Mach number of 2 at an altitude of $15 \mathrm{~km}$ (Fig. 1) and a Mach number of 5 at $30 \mathrm{~km}$ (Fig. 2). In both cases, the nozzle exhaust is produced by a generic engine operating at a combustion pressure of $110 \mathrm{bar}$ and an oxidizer to fuel ratio of 6.7. A reference solution ("full chemistry") was 


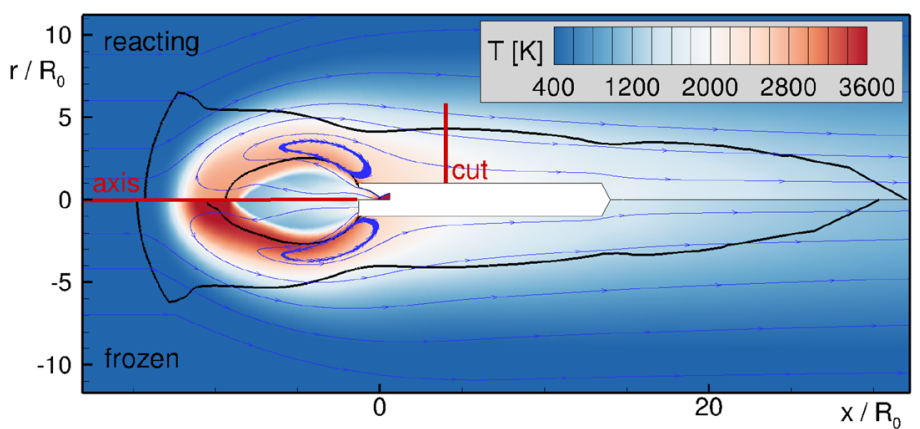

(a) Temperature fields in reacting and frozen flow conditions

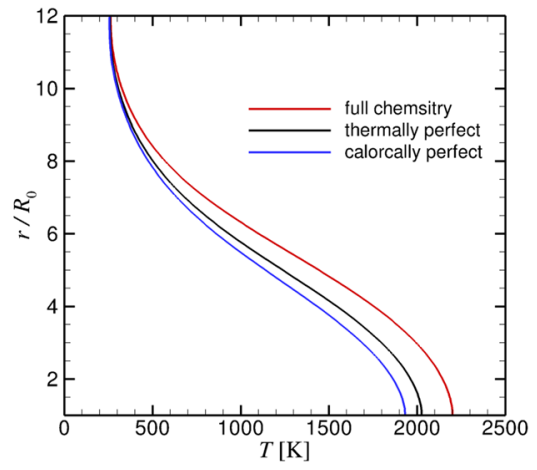

(b) Temperature profiles

Fig. 1 Influence of the exhaust plume chemistry in a representative test configuration (free stream Mach number of 2 at $15 \mathrm{~km}$ altitude)

Fig. 2 Influence of the exhaust plume chemistry in a representative test configuration (free stream Mach number of 5 at $30 \mathrm{~km}$ Altitude)

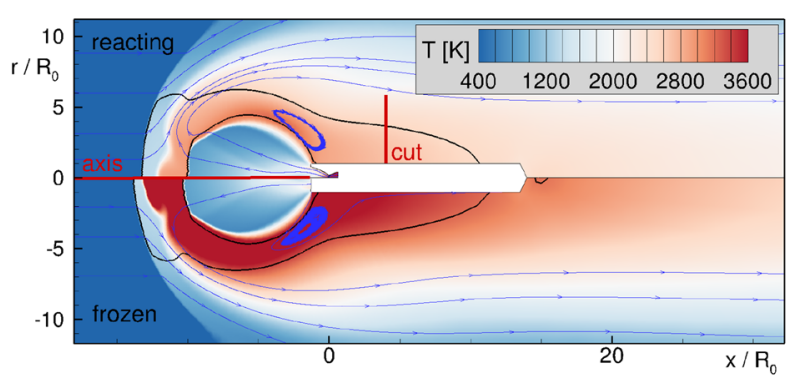

(a) Temperature fields in reacting and frozen flow conditions

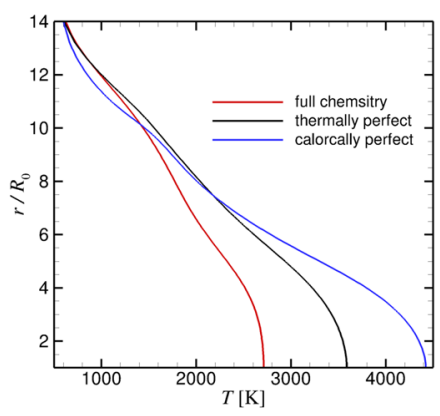

(b) Temperature profiles

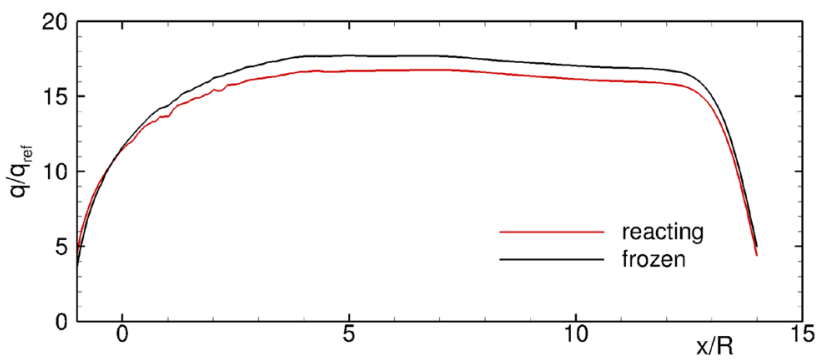

(c) Estimate of the surface heat flux

obtained by the application of a detailed 9 species, 19-step Jachimowski reaction mechanism [6].

The temperature distributions in the flow field in Figs. $1 \mathrm{a}$ and $2 \mathrm{a}$ show that the peak temperatures around the exhaust plume are generally lower in the reacting case. This is due to the presence of endothermal dissociation of exhaust jet combustion products. The principal plume structure is not affected. The cooling effect caused by the endothermal chemistry is significantly more pronounced for the Mach 5 conditions. This is due to the larger heating in the stagnation zone between plume and free stream which is primarily induced by the strong bow shock.

Figures Figs. $1 \mathrm{~b}$ and $2 \mathrm{~b}$ show the corresponding distributions of flow temperatures on a radial cut in the vicinity of the rocket surface for the Mach 2 and Mach 5 conditions, respectively. The cut position is indicated in the flow field visualizations. The cuts show different trends for the two considered free stream conditions.

At Mach 2, in the case of reacting flow, the value of the temperature close to the wall at $\mathrm{r} / \mathrm{R} 0=1$ is slightly higher 
than the value obtained under the hypothesis of a frozen gas mixture (labelled "thermally perfect" as the thermodynamic properties of the exhaust species are allowed to vary with temperature). The difference is approximately $10 \%$. This is due to the additional heat release by post-combustion of excess hydrogen in the fuel-rich exhaust plume of the engine. This additional heat release is not present for the frozen exhaust assumptions. The results for a calorically perfect gas (constant gas constant and ratio of specific heats) are also included for reference and are close to the thermally perfect results.

At Mach 5, the temperature of the reacting gas is significantly lower than the temperature at the frozen conditions. Here, contrary to the Mach 2 conditions, the effect of the absence of endothermal dissociation is dominant over the effect of extra heat release of excess fuel in the exhaust plume. The difference in gas temperatures between the frozen and reacting cases at the surface is about $30 \%$. The calorically perfect gas assumption leads to unphysical results.

The impact of the near wall gas temperatures on the surface heat flux distribution on the cylindrical rocked for the Mach 5 case is assessed in Fig. 2c. The Nusselt number, Nu, of a turbulent boundary layer scales with the Reynolds number, Re, as $N u \propto R e^{0.8}$. The flow velocity is nearly identical between the different cases (deviation of less than 1\%). Hence, under the additional assumption of negligible viscosity effects, the Nusselt number scales with a first-order approximation with the flow density as $N u \propto \rho^{0.8}$. The surface heat flux, $q$, can be estimated from the heat transfer coefficient, $\alpha$, the near wall gas temperature, $T$, and the wall temperature, $T_{w}$, as $q=\alpha\left(T-T_{w}\right)$, where $\alpha \propto N u$ if the influence of thermal conductivity is neglected. These relations are combined to:

$\frac{q}{q_{\text {ref }}}=\left(\frac{\rho}{\rho_{\text {ref }}}\right)^{0.8}\left(\frac{T-T_{w}}{T_{r e f}}\right)$

The results for $T_{\text {ref }}=1 \mathrm{~K}$ and $\rho_{\text {ref }}=1 \mathrm{~kg} / \mathrm{m}^{3}$ (used for nondimensionalization) are plotted in Fig. 2c. Despite the 30\% discrepancy of the near wall gas temperatures, the deviation between the heat flux estimates between reacting and frozen gas stays below $7 \%$. This is due to the lower densities at higher gas temperatures which counter-balance the temperature effect in the convective heat transfer problem.

In conclusion, this preparatory analysis shows that the frozen exhaust assumption yields realistic results for the surface heat flux. The error of the predicted gas temperatures is increasing with the free stream Mach number. General plume and flow field structures are not affected.

The plume characteristics and exhaust gas composition at the RETALT1 nozzle exit were obtained by a separate nozzle simulation. The results, including flow profiles at the exit, are shown in Fig. 3. The flow is assumed to be in chemical non-equilibrium and the Jachimowski reaction mechanism [6] is employed. The combustor conditions are characterized by a pressure of 117.3 bar and $\mathrm{O} / \mathrm{F}=6.7$. The fluctuations in the exit flow profiles are due to a complex and weak wave pattern which originates from the slightly non-perfect nozzle contour. The obtained flow profiles and the exhaust gas composition are then prescribed as an Dirichlet inlet condition at the nozzle exit planes in the 3D simulations of the RETALT1 rocket during the retro-maneuvers.

CFD simulations for the complete launcher are performed using half model for the ascent and a quarter-symmetry model for the descent. The hybrid/unstructured computational grids include approximately $7.7 \mathrm{M}$ volumes.

\section{CFD results}

The ATDBs consist of a set of surface heat flux distributions from detailed CFD analyses, combined with appropriate interpolation algorithms. The CFD investigations are performed mainly around peak heating and at critical flow conditions. Complementary thermal loads at less critical flight conditions (low heating rates) are estimated using scaling laws and are represented by synthetic heat flux distributions. The heat flux scaling for the synthetic heat flux distribution was obtained using well established general relationships between the global heat loads and the free stream properties $[3,14]$ :
Fig. 3 Flow analysis of the RETALT1 thrust nozzle

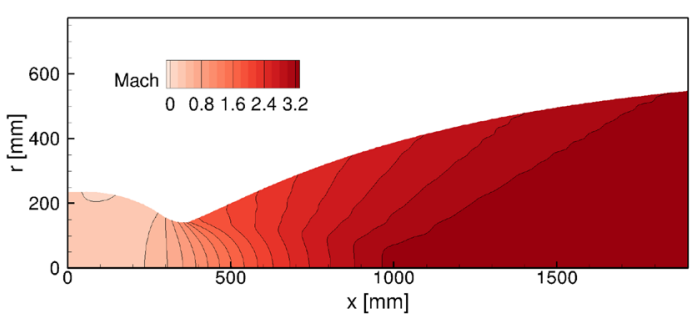

(a) Mach number distribution

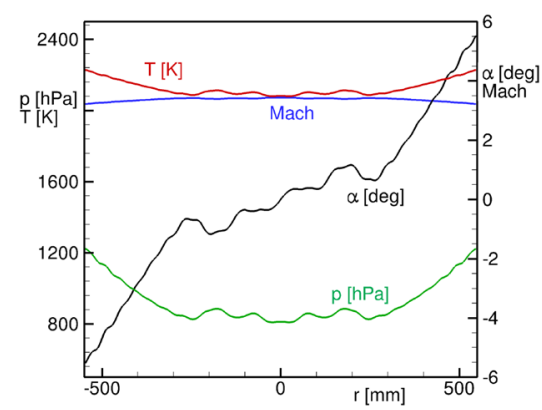

(b) Flow profiles at the nozzle exit 
$q_{\text {scaled }}=q_{\text {source }} \frac{\rho_{\text {scaled }}^{0.5} u_{\text {scaled }}^{3}}{\rho_{\text {source }}^{0.5} u_{\text {source }}^{3}}$

Here, $q_{\text {scaled }}$ is the local synthetic heat flux value for a fixed wall temperature, $q_{\text {source }}$ is a CFD heat flux distribution which serves as the scaling source, $\rho$ and $u$ are the free stream densities and flight velocities, respectively.

Initial qualitative estimates of the global aerothermal heating are used to identify critical flight regimes. They are obtained using the Sutton-Graves approximation [14] in Eq. 3 , where $R_{n}$ represents the body bluntness.

$q_{s}=1.7415 E^{-4}\left(\frac{\rho}{R_{n}}\right)^{0.5} u^{3} \quad\left[\frac{\sqrt{k g} m}{s^{3}}\right]$

\subsection{RETALT1 mission}

The RETALT1 launcher is a Two Stage To Orbit (TSTO) launcher with the objective to transfer a payload of 20tons to a Low Earth Orbit (LEO) of approximately $340 \mathrm{~km}$.

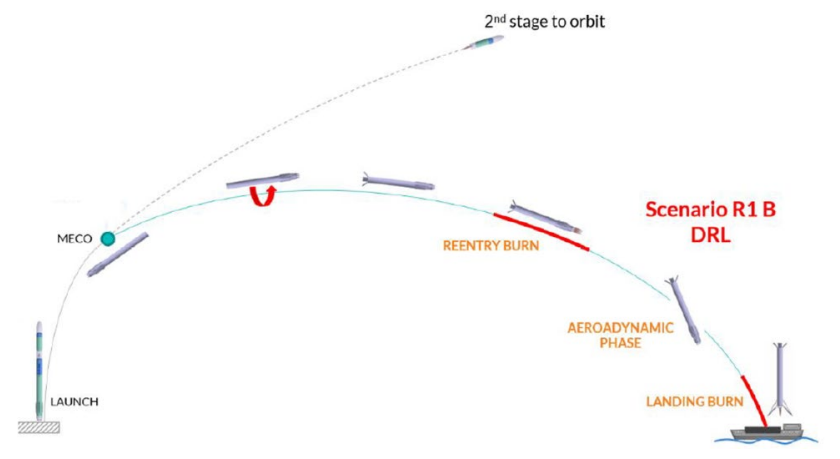

- The first stage has 9 engines that will be active until Main Engine Cut Off (MECO)

- Right after MECO, the second stage main engine ignites and completes the injection of the payload to orbit

- The first stage continues the flight along a ballistic trajectory outside of the atmosphere. Before entry, the vehicle is turned in a flipover maneuver. After entering the upper atmosphere, the re-entry burn is initiated to reduce the flight speed. This is followed by an aerodynamic unpropelled flight phase, which is terminated by a landing burn to ensure a controlled touchdown.

A sketch of the mission is shown in Fig. 4.

\subsection{Ascent trajectory}

This section is devoted to the discussion of representative flow field solutions for RETALT1 during the ascent phase, that is the timespan ranging from take-off until MECO. In this phase, all the 9 engines of the first stage are active and the second stage is still present.

The ascent trajectory is represented by the solid black line in Fig. 5a. Symbols illustrate the database population, black filled circles represent the computed trajectory points (\# 1-6). Concerning the ascent flight, the heat flux distribution below point \# 1, at $66 \mathrm{~s}$, is considered to be constant. During subsonic flight, aero-thermal heating of the external surfaces is negligible. Base plate heating stays approximately constant due to the similar flow structure at low altitudes.

The last point of the trajectory (\# s6) is obtained by scaling the aerothermal heating using Eq. 2. The heat flux distribution at the base plate was not scaled because it is dominated by the plume structure and the associated recirculation patterns which, at high altitudes, are not affected by the free stream conditions.

Fig. 4 Concept scenarios for RETALT1 mission [1]

Fig. 5 RETALT1 Ascent trajectory points and flight conditions

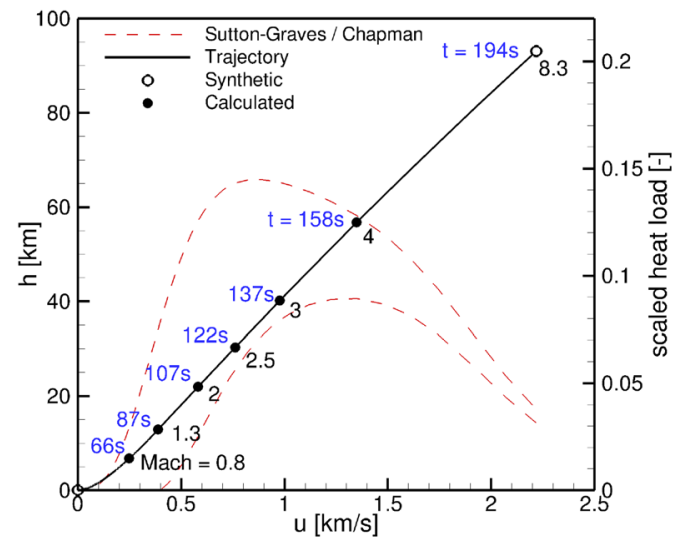

(a) Ascent trajectory

\begin{tabular}{cccc}
\hline$\#$ & Time $(\mathrm{s})$ & $\mathrm{h}(\mathrm{km})$ & Mach \\
\hline $\mathrm{s} 1$ & 0 & 0 & 0 \\
1 & 66,35 & 6,78 & 0,8 \\
2 & 86,53 & 12,92 & 1,3 \\
3 & 107,4 & 21,96 & 1,99 \\
4 & 122,4 & 30,29 & 2,52 \\
5 & 137,25 & 40,13 & 3,07 \\
6 & 158,2 & 56,75 & 4,16 \\
$\mathrm{~s} 6$ & 194 & 93 & 8,3 \\
\hline
\end{tabular}

(b) Database population for ascent configuration 
The trajectory point \# s6 is characterized by a Knudsen number of 0.1 which is at the edge of continuum. In this flow regime, velocity and temperature slip at the wall can already occur. Hence, the scaling approach described at the beginning of Sect. 3 would result in a conservative estimate of the heat fluxes. Due to the very low heat flux values, the error made by using the scaling approach, based on the continuum assumption, is negligible. However, $\mathrm{Kn}=0.1$ justifies the adoption of the continuum model since the Navier-Stokes equations still represent a reasonable approximation of the flow physics.

Details of the considered trajectory points are given in Fig. 5b.

Representative flow field structures for the RETALT1 ascent flight are shown in Figs .6 and 7 and permit this analysis of typical phenomena occurring in low- and highaltitude mode, respectively.

The images on the left-hand side show the colored pressure coefficient distribution, while the Mach number in the symmetry plane is in gray-scale. The brown iso-surface represents the boundary of 50\% exhaust mass fraction and indicates the geometrical extent of the engine plumes. On the right-hand side, the distribution of surface heat flux is shown in color; gas temperatures in the symmetry plane are shown in gray scale. The brown iso-surface depicts the region of flow reversal and recirculation with the axial velocity $u<-100 \mathrm{~m} / \mathrm{s}$.

At low altitudes with a large atmospheric ambient pressure, the exhaust plumes are confined and the intensity of plume-plume interactions is comparatively limited (Fig. 6a). The flow reversal region surrounds the cluster of engines and it is characterized by a limited length. The thermal loads on the base plate are rather low (Fig. 6b).

At higher altitudes, the ambient pressure is lower and consequently the plumes are significantly spread out. Strong plume-plume interaction occurs in the vicinity of the launcher base (Fig. 7a). The flow reversal region is located around the central nozzle and between the lateral nozzles. It
Fig. 6 RETALT1 ascent flow field structure (low altitude mode, $h=22 \mathrm{~km}, \mathrm{Mach}=2$ )
Fig. 7 RETALT1 ascent flow field structure (high-altitude mode, $h=40 \mathrm{~km}, \mathrm{Mach}=3$ )

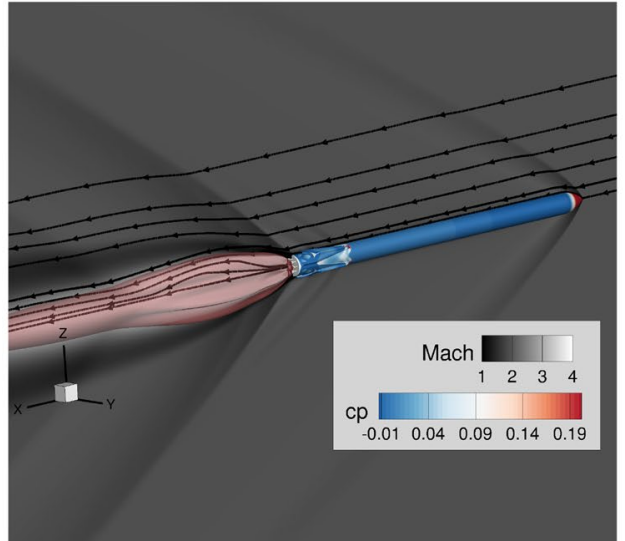

(a) Iso-surface of $50 \%$ exhaust mass fraction, Mach, surface pressure

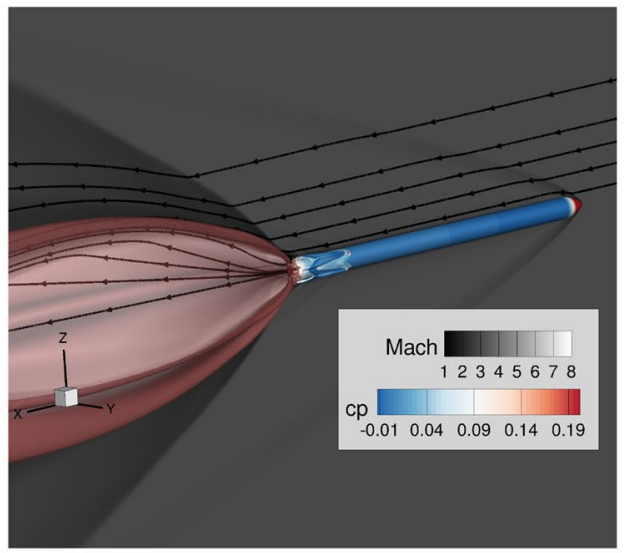

(a) Iso-surface of $50 \%$ exhaust mass fraction, Mach number, surface pressure

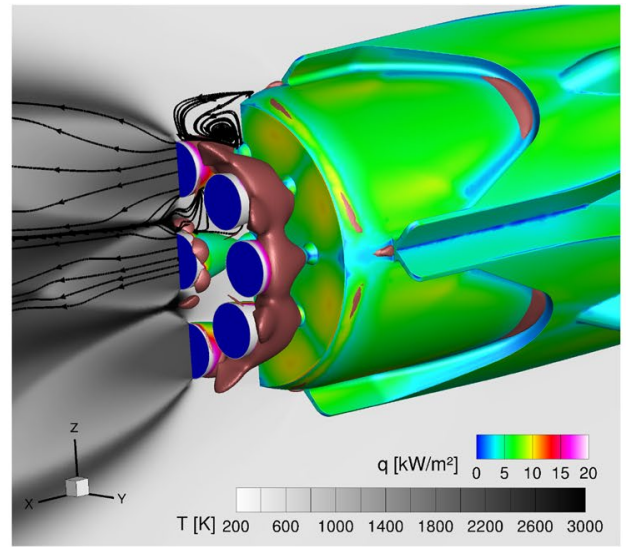

(b) Iso-surface of strong flow reversal, temperature, surface heat flux

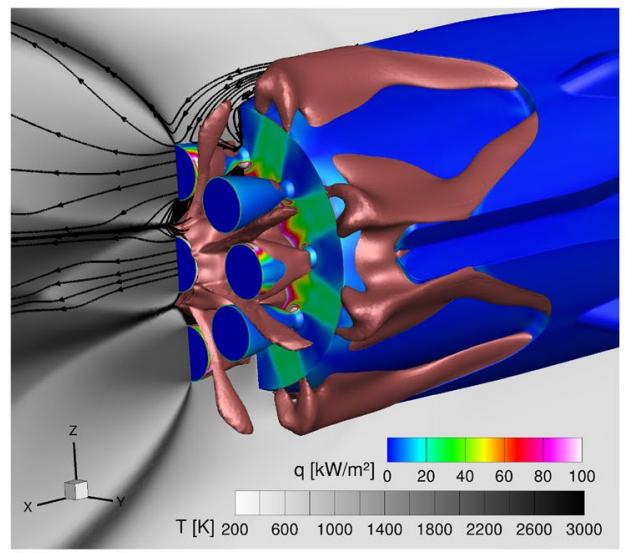

(b) Iso-surface of strong flow reversal, temperature, surface heat flux 
also spreads slightly ahead the base plate close to the protrusions created by the folded landing legs (Fig. 7b). The transition between the different flow modes occurs in a very narrow range of altitudes and the recirculation of hot exhaust gases in the high-altitude mode strongly increases the base heating.

The rapid transition between the flow modes is visible in the histories of the averaged heat fluxes on the nose and base plate which are shown in Fig. 8 for different wall temperatures. The nose heating at low flight velocities $(t<140 s$, $M=3$ ) is dominated by the difference of the wall and ambient temperature (heating for $T_{w}=200 \mathrm{~K}$, cooling for $T_{w}>T_{\text {ambient }}$ ). The local heating or cooling efficiency is at a maximum in the nose region and at surface protrusions. At high flight velocities $(t>150 s, M>4)$, the nose heating curves collapse as the total temperature is significantly larger than the wall temperature. Nevertheless, the heat fluxes in this flight regime remain rather small due to the higher altitude.

Concerning the base plate, at low altitudes $(t<110 s)$, the heat loads remain generally small and are dominated by

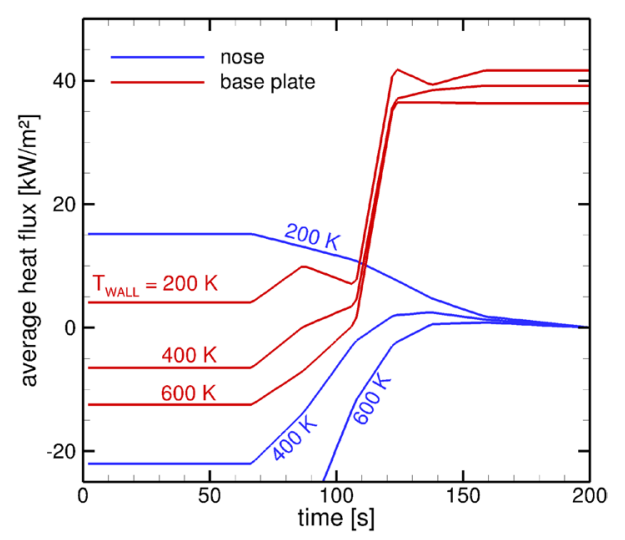

Fig. 8 RETALT1 time histories of average heat flux for constant wall temperatures - ascent phase the difference between the wall and ambient temperatures (similar as for the nose heating), see Fig. 8.

The base flow topology in this flight regime is characterized by confined plumes, weak plume-plume interaction and a weak recirculation region of hot exhaust gases. A typical heat flux pattern is shown in Fig. 9a. At higher altitudes, the influence of the free stream on the exhaust plumes becomes negligible and the heating patterns are dominated by an octagonal star-like structure (see Fig. 9b). This structure represents the footprint of the recirculation pattern of hot exhaust gases which is driven by the strong plume-plume interaction. The highest heat loads occur at this flight regime. Local maxima are in the order of 100 $\mathrm{kW} / \mathrm{m}^{2}$ and occur close to the baseplate openings of the outer nozzle ring.

\subsection{Descent trajectory}

Right after MECO, the RETALT1 first stage performs a downrange landing maneuver. For sake of brevity, RETALT1 first stage will be referred simply as RETALT1 from now on. The descent trajectory is shown in Fig. 10a.

- The blue line represents the unpropelled flight, the vehicle altitude decreases from $91.72 \mathrm{~km}$ to $67.51 \mathrm{~km}$.

- The red line indicates the retro-burn phase which is performed with 3 of 9 engines in operation. At the end of this phase, the vehicle reaches an altitude of $34.43 \mathrm{~km}$.

- The retro-burn phase is followed by a second unpropelled flight phase (shown in green), which finishes at an altitude of $1.9 \mathrm{~km}$.

- Finally, the landing phase is performed using retro-burn of the central engine only. This part of the trajectory is represented by the purple line.

The dashed black line provides an estimation of the heat flux in the stagnation point downstream the entry bow shock and it is obtained using Eq. 3. Such empirical relation can be effectively applied during the atmospheric flight, but it is
Fig. 9 RETALT1 ascent heat flux distributions on the base plate

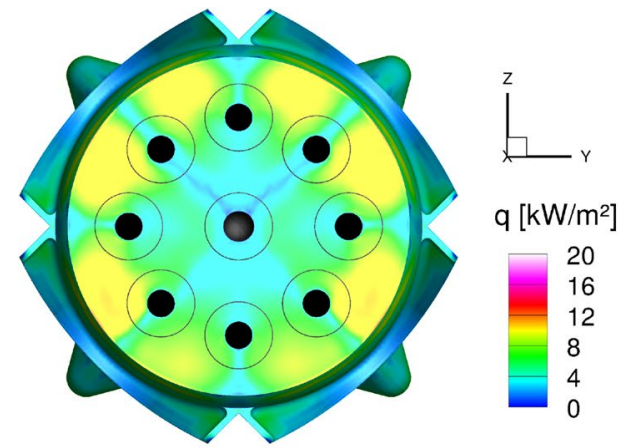

(a) low altitude mode, $\mathrm{h}=22 \mathrm{~km}, \mathrm{Mach}=2$

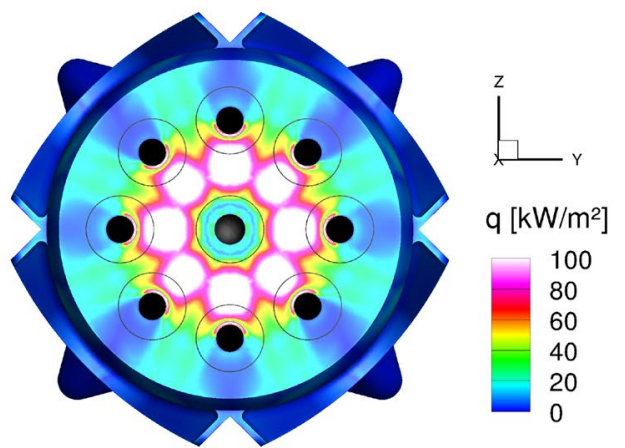

(b) high altitude mode, $\mathrm{h}=40 \mathrm{~km}, \mathrm{Mach}=3$ 
Fig. 10 RETALT1 Descent trajectory points and flight conditions

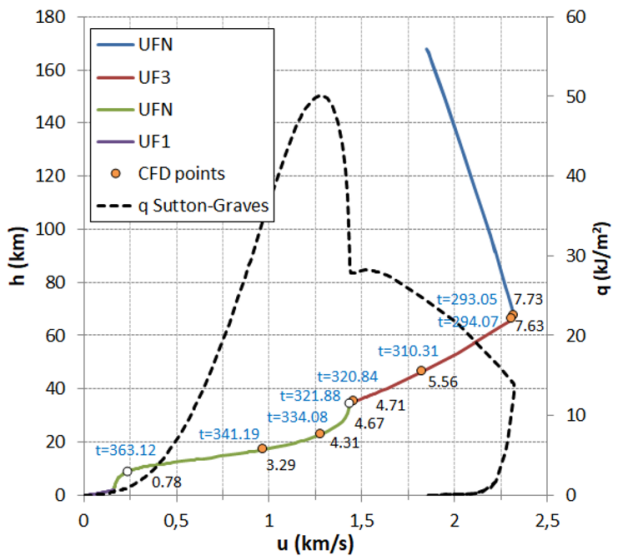

(a) Descent trajectory

\begin{tabular}{rccc}
\hline$\#$ & Time $(\mathrm{s})$ & $\mathrm{h}(\mathrm{km})$ & Mach \\
\hline 1 & 293,048 & 67,515 & 7,73 \\
2 & 294,066 & 66,178 & 7,63 \\
3 & 310,311 & 46,321 & 5,561 \\
4 & 320,838 & 35,375 & 4,71 \\
$\mathrm{~s} 5$ & 321,857 & 34,419 & 4,665 \\
5 & 334,084 & 22,962 & 4,313 \\
6 & 341,195 & 17,187 & 3.291 \\
$\mathrm{~s} 6$ & 363.105 & 8,848 & 0,777 \\
\hline
\end{tabular}

(b) Database population for descent configuration not able to provide meaningful results in the retro-propulsion regime, due to the completely different physical phenomena.

Orange symbols indicate trajectory points for which CFD-analyses were performed (\#1-6) instead the white symbol (\#s6) indicates synthetic heat flux data computed by means of Eq. 2. The use of a scaled solution is justified by the fluid-dynamic conditions that are not critical for the aero-thermal loads.

The free stream conditions in each CFD point are summarized in Fig. 10b. Point \#1 is taken at the end of the first unpropelled phase and is characterized by a high altitude and a high Mach number. The second CFD point \#2 is at the beginning of the first retro-burn phase. Altitude and Mach are comparable to case \#1 but the difference lays in the presence of the three operative engines. Points \#3 and \#4 are located in the middle and at the end of the first retro-burn phase, respectively. Finally, points \#s5-s6 are chosen in the second un-propelled phase, when the vehicle has already reached low altitudes. CFD computations were performed at each point using fixed wall temperatures of $200 \mathrm{~K}$ and $600 \mathrm{~K}$ in order to take into account the influence of the local surface temperature on the aero-thermal heating in the database. Since the flow field structures are not dramatically affected by the wall temperature, only results obtained for $T_{w}=200 \mathrm{~K}$ are shown. The scaling of the synthetic solution was also treated separately for all considered wall temperatures.

\subsubsection{Retro burn}

Representative flow field solutions for the RETALT1 during the entry trajectory are shown in Figs. 11 and 12 for the configuration with 3 operative engines, and in Fig. 16 for the case without engines. The distribution of the pressure coefficient (left-hand side pictures) and surface heat flux (righthand side pictures) are shown in color; Mach number and gas temperature in the symmetry plane are shown in grayscale. In the left-hand side pictures, the brown iso-surface represents the boundary of $50 \%$ exhaust mass fraction and indicates the geometrical extend of the engine plumes. The streamlines are coloured by the longitudinal velocity component. In the right-hand side pictures, the brown iso-surface depicts the region of the flow field where $u=-100 \mathrm{~m} / \mathrm{s}$ to visualize the back flow. The retro-burn begins when the vehicle is still at high altitude and high Mach, the free stream conditions are described in Fig. 10b, trajectory point \# 2 . Due to the low static free stream pressure, the plume significantly spreads downstream and upstream the vehicle which is totally immersed in a hot atmosphere made up by a large percentage of exhausted gas (see Fig. 11a). The value of the pressure coefficient, on the RETALT1 body, ranges between -0.02 and 0.3 , higher values can be seen on the base plate especially in the vicinity of xy-symmetry plane and on the lateral surface of the central nozzle, close to the exit plane $\left(c_{p}=1.93\right)$. The streamlines indicate the presence of a large recirculation area surrounding the bottom part of the vehicle immediately downstream of the exhaust plume structure. The backflow is displayed by means of the brown iso-surface in Fig. 11b, it redirects hot exhaust gases towards the base plate (similar to the high altitude mode during ascent) and spreads mainly in the transverse direction with respect to the axis in which the operative engines lay. The same picture shows the heat-flux distribution on the vehicle surface and the temperature field in the symmetry plane. Despite the hot gas surrounding the launcher the heat flux peaks remain low which is primarily due to the low density of the flow field: $q_{\text {base plate }}=69 \mathrm{~kW} / \mathrm{m}^{2}$ and $q_{\text {planar fin }}=57 \mathrm{~kW} / \mathrm{m}^{2}$.

A flow field solution of particular interest is the one at the end of retro-propulsion due to the severe thermal loads occurring on the aerodynamic control surfaces which directly face the incoming flow being heated in the upstream stagnation zone (see Fig. 12b). The heat flux here is the 
Fig. 11 RETALT1 descent flow field structure (high altitude mode, $h=66 \mathrm{~km}$, Mach=7.6), beginning of retro-propulsion
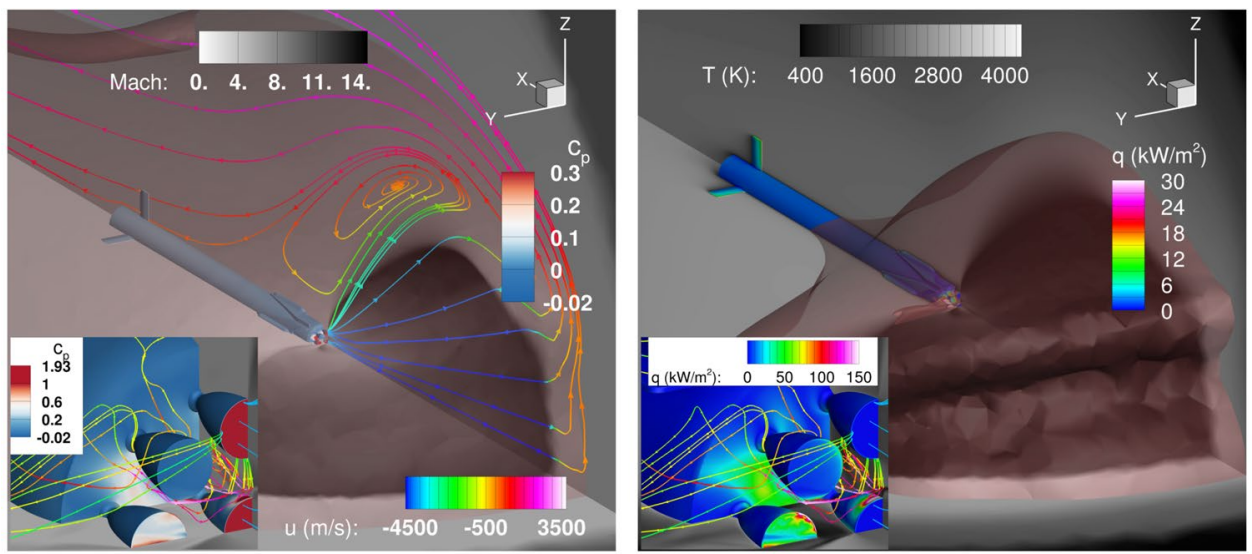

(a) Iso-surface of $50 \%$ exhaust mass fraction, Mach number, surface pressure

(b) Iso-surface of strong flow reversal, temperature, surface heat flux

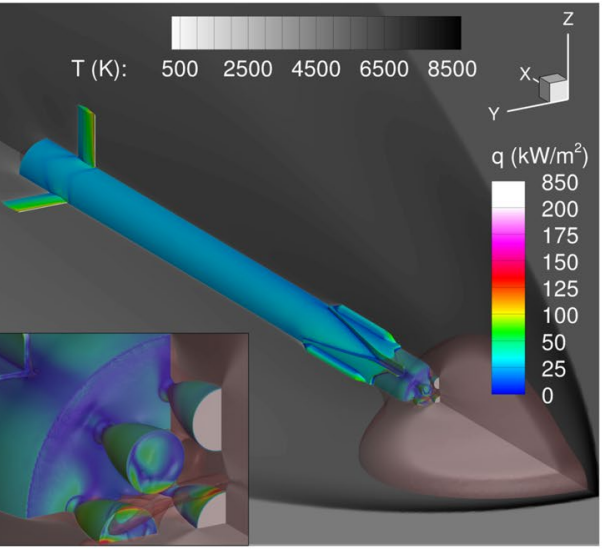

(b) Iso-surface of strong flow reversal, tem- (a) Iso-surface of $50 \%$ exhaust mass fraction, Mach number, surface pressure

perature, surface heat flux

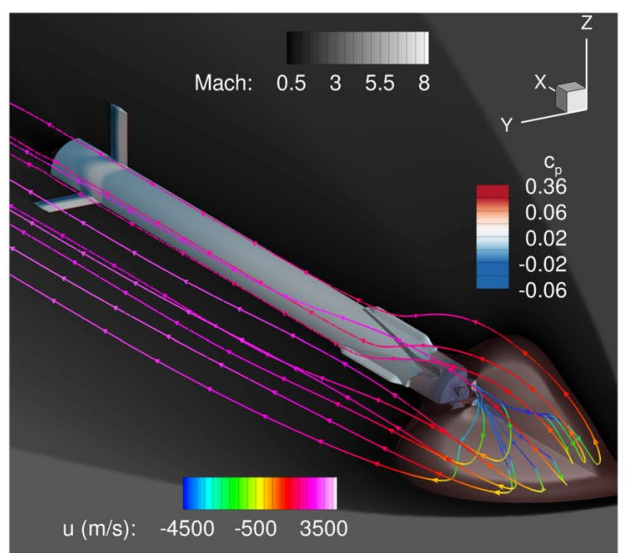

Fig. 12 RETALT1 descent flow field structure (midrange-altitude mode, $h=35 \mathrm{~km}$, Mach=4.7), end of retropropulsion highest among the CFD points analysed, and can be regarded as the dimensioning value for the planar fins design. Free stream conditions are described in Table $10 \mathrm{~b}$ trajectory point \# 4 and represent an example of mid-range altitude mode. Due to the moderate densities and the fact that the flow is aligned parallel to the vehicle surface, the heat fluxes on the central body remain moderate. The base plate heating is significantly reduced during the retro-burn due to the efficient shielding effect of the exhaust plume. The backflow region is significantly smaller compared to the beginning of retropropulsion (high-altitude mode); here, the brown iso-surface is confined in a limited area downstream the launcher and spreads slightly upstream the base plate.

An important reduction of the exhaust plume size can be observed in Fig. 12a and is due to the increasing static and dynamic free stream pressure that occurs towards the end of the retro-burn. In this case, only the lower part of the launcher is immersed in an atmosphere rich of hot exhausted gases. The pressure coefficient distribution is in the range
[-0.06, 0.08], on the planar fins $c_{p}$ is slightly higher and reaches 0.35 .

\subsubsection{Parametric studies and uncertainty assessment for the retro-burn phase}

Complementary 2D investigations have been performed to verify the reliability of the 3D results in terms of peak heat flux on the planar fin's leading edge. The aim was to demonstrate that the spatial resolution of the $3 \mathrm{D}$ grid used in the CFD simulations is sufficient for an accurate representation of the heat flux level on the aerodynamic control surfaces.

To achieve this goal, two different 2D grids are used: the first one is characterized by a high-resolution (Fig. 13a) and the second one is characterized by the same spatial resolution as the 3D grid (Fig. 13b). The latter is coarser if compared to the former, indeed 3D simulations require a carefully evaluation of computational costs. 
The flow field conditions at the end of the retro burn are chosen for the grid sensitivity analysis because they provide the most critical thermal load on the leading edge of the planar fin. As a consequence, such conditions impose the most severe constraints on the spatial discretization of the boundary layer.

The free stream conditions were extracted from the 3D flow field in a point located $30 \mathrm{~cm}$ upstream of the leading edge at mid-length of the planar fin. This distance corresponds to the stand-off distance of the bow-shock at the root of the planar fin.

The free stream conditions are listed below.

- $M=1.5139$

- $p=581.877 \mathrm{~Pa}$

- $\rho=3.2067 E^{-4} \mathrm{~kg} / \mathrm{m}^{3}$

The heat flux distributions along the planar fin profile, obtained by 3D and 2D simulations, are shown in Fig. 14 . The 3D simulation shows a heat flux peak on the leading edge followed by a sudden drop and a successive increase that creates a "valley effect" which is attributed to the coarse spatial resolution in the vicinity of the strong jump in curvature at the downstream end of the leading edge. After the local maximum, the heat flux decreases regularly. Except for the "valley effect", both 2D simulations reproduce the $3 \mathrm{D}$ trend very well. The $2 \mathrm{D}$ simulation performed using the high-resolution grid (red line) provides a maximum value $7.59 \%$ lower than the $3 \mathrm{D}$ one. The use of the grid characterized by 3D equivalent spatial resolution provides a value that matches the $3 \mathrm{D}$ result. From these results, one can conclude that 3D mesh provides a reliable representation of thermal loads on planar fins.

To assess the effects of the turbulence model on the thermal loads occurring on the launcher surface and on the external flow field, a sensitivity analysis has been performed. Besides the Spalart-Allmaras model (SA), which has been used as baseline for the CFD simulations that make up the ATDB, the Shear Stress Transport $k-\omega$ (SST) in the formulation written by Menter in 1994 [12] and Wilcox $k-\omega$ model [15] have been investigated. The results are compared in Fig. 15.

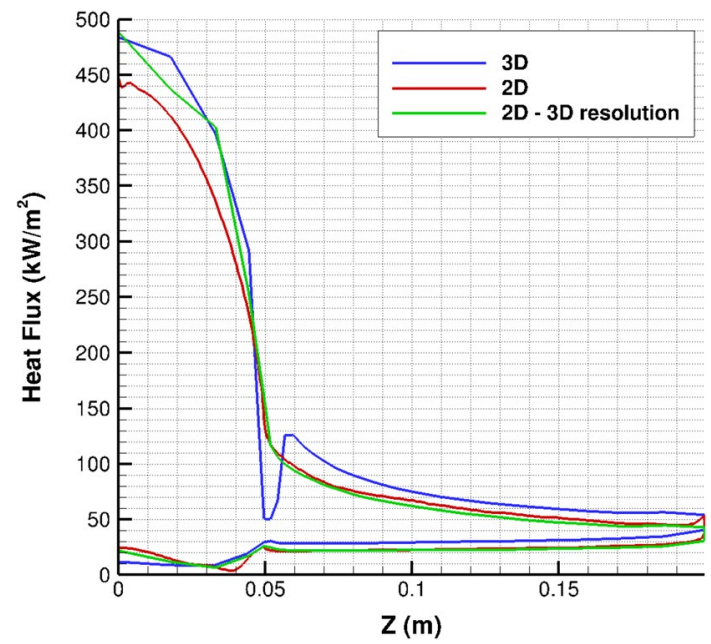

Fig. 14 Heat flux comparison on the planar fin profile

The structure of the external flow field exhibits considerable changes depending on the turbulence model used. The comparison of the Mach number fields obtained with the SA and SST model, see Fig. 15a, shows that the extension of the jet in the radial direction, identified by the barrel shock, is larger when the SST model is used. In this case, the oblique shock, which decelerates the engines exhausted gases, is reflected on the symmetry axis with a Mach reflection. The Mach stem is clearly visible in the lower part of the central frame. It is interesting to note that the stand-off distance of the bow shock is the same for both turbulence models. When the SA model is used, the oblique shock has an intensity such that the reflection on the symmetry axis occurs through the creation of another oblique shock. In both cases, the weak reflected shocks dissipate quickly in the subsonic stagnation zone which develops between bow and barrel shocks. They are not visible in the graphs.

Fig. 15a shows also the comparison between the thermal loads obtained with SA and SST turbulence models. It is noteworthy that the thermal loads on the leading edge of the planar fins are more intense in the case of SST model. In this case, the heat flux is rather uniform along the leading edge, except for the fin root. When the SA model is used, the heat flux value reaches its maximum towards the tip, elsewhere
Fig. 13 2D Grids used for the convergence analysis on the planar fin

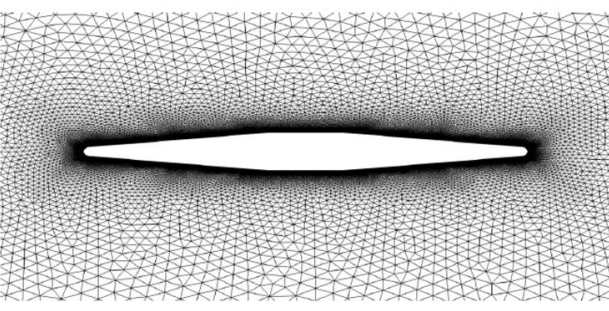

(a) Fine grid

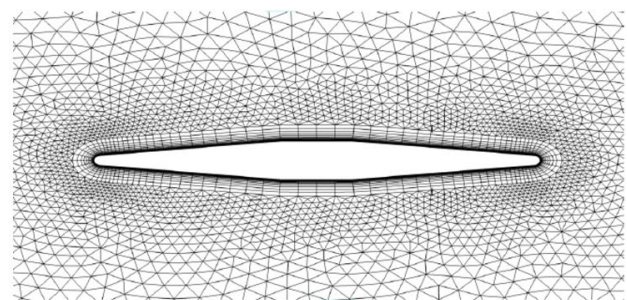

(b) Coarse grid (3D equivalent) 


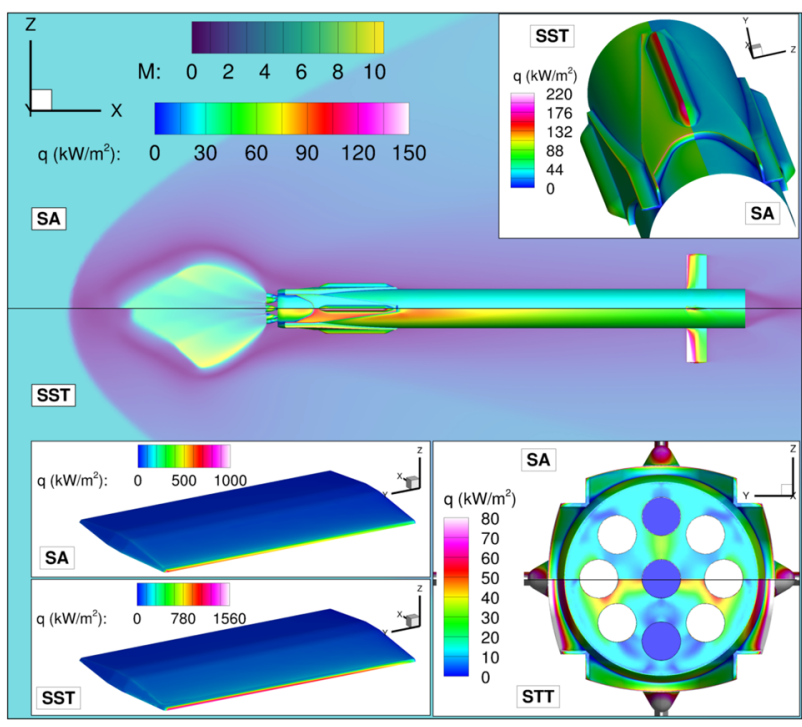

(a) Spalart-Allmaras (SA) vs. Shear Stress Transport $k-\omega$ (SST)

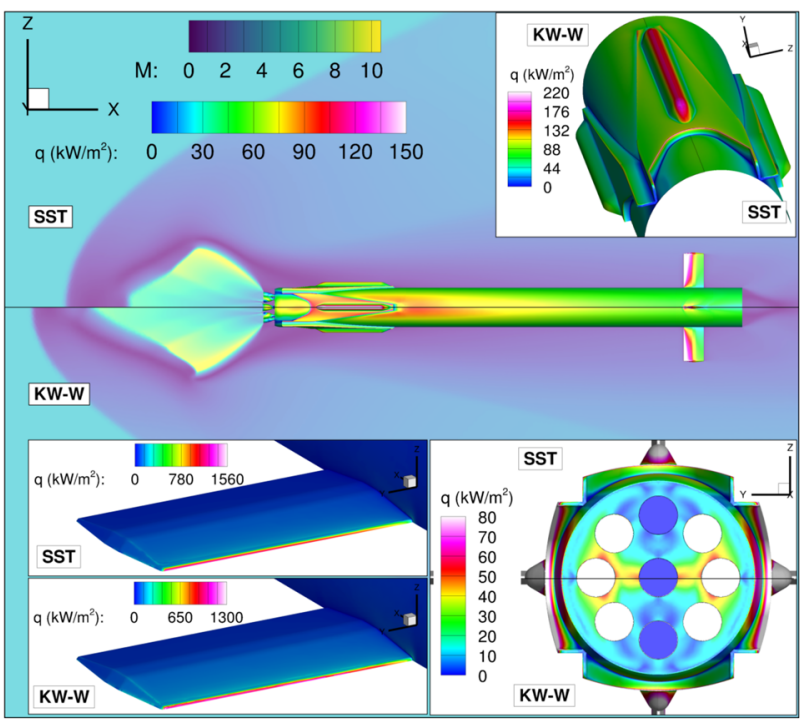

(b) Shear Stress Transport $k-\omega(\mathrm{SST})$ vs. Wilcox $k-\omega(\mathrm{KW}-\mathrm{W})$

Fig. 15 Sensitivity analysis on turbulence modelling, heat flux surface distribution and Mach field $\left(h=35 \mathrm{~km}, \mathrm{Mach}=4.7, T_{w}=600 \mathrm{~K}\right)$

it is quite low. The significant disparity in surface heat flux distributions between the SA and SST models for the retro burn case is primarily caused by different predictions of the recirculation structure of the hot exhaust plumes. Moderate changes in the plume and vortex structures alter the impact angle and velocity of the hot gases on the surfaces and the resulting heat flux levels. Further, in the high supersonic flow regime the Spalar-Allmaras model tends to a slightly delayed turbulence production inside the boundary layers which reduces the heat loads.

Significant differences can be also detected in the heat flux values on the base plate, folded legs and cylindrical body, especially the bottom part. Considering the base plate, the aero-thermodynamic heating exhibits a different pattern according to the turbulence model used for the simulation. If $\mathrm{SA}$ is considered, the highest heat flux values are located between the operative engines (Z-axis). With SST, instead, they can be found on the transverse direction ( $Y$-axis). The reason for these differences lies in the different shape and size of the plume in radial direction which leads to different patterns of hot exhausted gases. The resulting heat flux differences are about $35 \%$ on the base plate and the planar fin's leading edge up to $120 \%$ on the launcher body.

The results of the simulations carried out with the two equations turbulence models SST and Wilcox $k-\omega$ are shown in Fig. 15b. The heat flux pattern is very similar, nevertheless the use of Wilcox $k-\omega$ leads to higher values on the cylindrical body above the folded legs connection point. On the leading edge, the heat flux provided by Wilcox $k-\omega$ has a similar distribution compared to the case with SST, but the peak value is $17 \%$ lower. The major discrepancies appear in the external flow field, where the stand-off distance of the bow shock is larger for Wilcox $k-\omega$ and in the region where the barrel and the oblique shocks come in contact the Mach flow field is less smooth. On the other hand, the radial size of the plume is comparable. This causes the similar heat flux patterns on the lower part of the vehicle.

The data collected by means of this sensitivity analysis highlight the presence of significant modelling uncertainty due to turbulence models. The lack of experimental data does not allow the assessment of which turbulence model provides the most accurate representation of the physical flowfield. Future work in the RETALT project aims to accommodate the strong need for validation data by means of a campaign of dedicated experiments.

The use of the Spalart-Allmaras model, as a baseline for the CFD simulations which make up the aero-thermal database, is preliminarily justified by indications from comparisons to LES data in previous studies [4]. The influence of the turbulence modelling for the aerodynamic trajectory phase (no operational engines) is expected to be significantly less.

\subsubsection{Aerodynamic (un-propelled) flight phase}

The first retro-burn phase is followed by a second un-propelled phase. Point \#5 is chosen at an altitude of $22.96 \mathrm{~km}$, where the free stream static pressure and density are one order of magnitude larger than the respective ones at point \#4. The pressure coefficient is higher than for CFD points $\# 1-4$, the maximum value on the base plate is 1.77 , whereas on the planar fin it is 1.29. Streamlines shown in Fig. 16a show that the bow shock is close to the base plate and the flow passes through the cluster of thrust nozzles. The Mach number distribution in Fig. 16a shows a complex pattern of shocks and rarefaction waves in the folded legs region. 
The heat flux contour plot and the temperature field in the symmetry planes are shown in Fig. 16b. Although the temperature behind the shock is lower compared to CFD points previously analysed, thermal loads on base plate and planar fins are significant, $q_{\text {planar fin }}=280 \mathrm{~kW} / \mathrm{m}^{2}$ and $q_{\text {base plate }}=360 \mathrm{~kW} / \mathrm{m}^{2}$ respectively. The stagnation zones that form behind the shock move close to the base region and a backflow develops around the central engine and spreads radially towards the external nozzles. This high heat flux value on the base plate has three main reasons: the absence of the protective retro plume; the larger density compared to the retro-burn cases in the vicinity of the base; and the flow velocity directed towards the base structure (contrary to the flow field with plumes).

\subsubsection{Time histories of heat loads}

The time histories of the averaged heat fluxes on the base plate and on a planar fin, during the descent trajectory, are shown in Fig. 17. Considering the base plate (Fig. 17a), it is possible to observe that the average heat flux remains approximately constant during retro-propulsion because of the exhaust plume shielding effect. Once the engines are turned off, the average heat flux goes through a sudden increase due to the presence of the bow shock and the associated aero-thermal heating close to the base plate. Between trajectory points $\# 5 \mathrm{~s}-5$, the average heat flux slightly decreases, indeed in this part of the trajectory, the flow conditions do not change significantly, and then rapidly declines due to the strong reduction of the flight velocity.

Before discussing the averaged heat flux time evolution on a planar fin (Fig. 17b), it is worth specifying that in these cases the averaging process provides information that needs to be read with caution. In fact, the heat flux on the planar fin reaches high values along the entire leading edge with a peak around the tip, elsewhere the heat flux is significantly lower. Because of the presence of strong local effects, the time histories of averaged heat flux on the leading edge are provided for both the wall temperatures $(200 \mathrm{~K}$ and $600 \mathrm{~K})$ and are represented by dashed lines.
Fig. 16 RETALT1 descent flow field structure (low altitude mode, $h=23 \mathrm{~km}$, Mach $=4.3$ ), aerodynamic phase

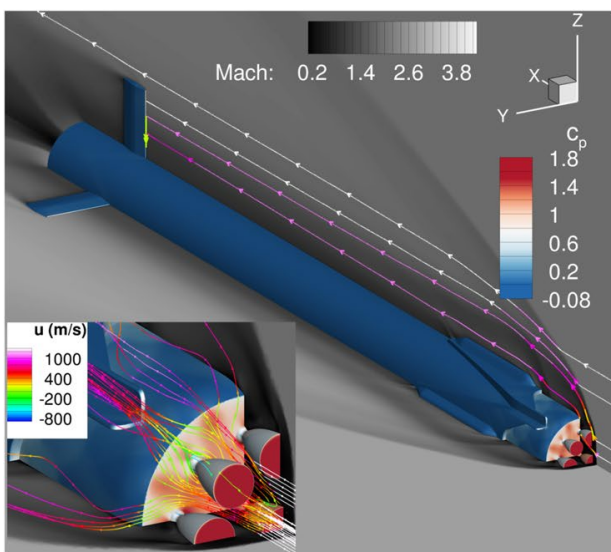

(a) Mach number, surface pressure

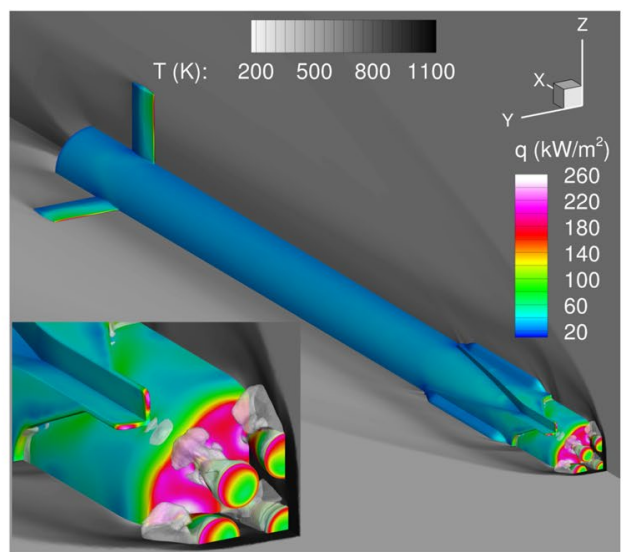

(b) Iso-surface of strong flow reversal, temperature, surface heat flux
Fig. 17 RETALT1 time histories of average heat flux for constant wall temperatures descent phase

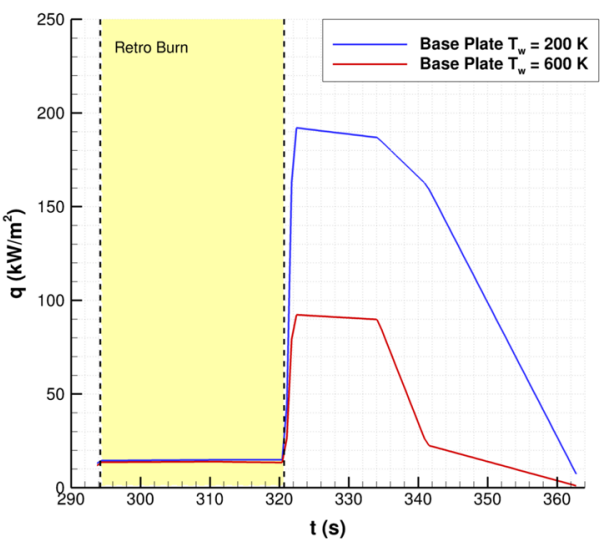

(a) Base plate

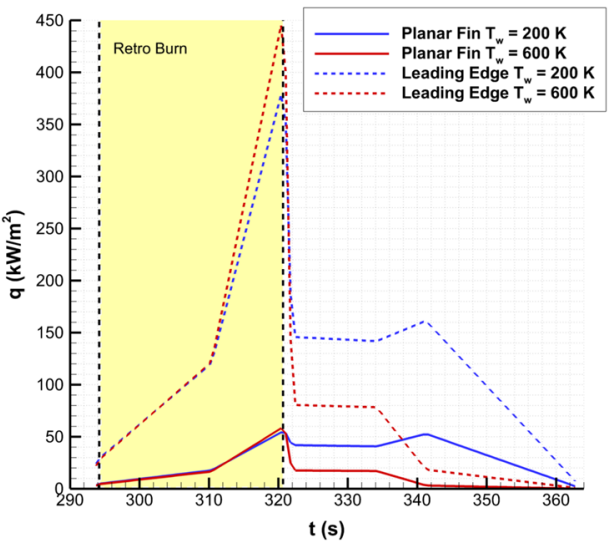

(b) Planar fin and leading edge 
Fig. 17b shows that the averaged heat flux on the overall planar fin increases for the entire retro-propulsion duration due to the fact that the aerodynamic control surface directly face the incoming flow being heated in the upstream stagnation zone. After having reached the maximum heat flux at the end of the retro burn, it drops because hot exhaust gases are blown away. The curves in Fig. 17b exhibit a plateau between trajectory points \#5s-5, then they show different trends depending on the wall temperature.

For $T_{w}=600 \mathrm{~K}$ (red line) the average heat flux decreases because of the strong reduction in flight velocity. Concerning $T_{w}=200 \mathrm{~K}$ (blue line) the average heat flux starts increasing again and reaches a local maximum. This effect is due to the heating provided by the surrounding atmosphere; in this case, the air is hotter than the planar fin.

The time histories of the averaged heat flux on the leading edge (dashed lines) follow the same qualitative trend of the overall fin, but levels are significantly higher $(\approx 86 \%$ evaluated at the peak) proving that this region is the most critical in terms of thermal loads.

\subsubsection{Exemplary application of the aero-thermal database}

The detailed local heat flux data from the CFD analyses are organized in an aero-thermal database. This allows estimating the local heat flux at each point of the surface as a function of the current flight time and the local wall temperature. This surrogate model for the aero-thermodynamic heating can be easily coupled to a structural response model to evaluate the temperature history during atmospheric flight for each location on the vehicle surface.

To illustrate the coupling process and the application of the aero-thermal database, the local surface temperature history of RETALT1 is computed during the entire atmospheric ascent and return flight. A simple lumped mass method that represents the instantaneous heating of a $5 \mathrm{~mm}$ aluminium structure was employed as the structural response model for this example. The material properties are summarized in Table 1.

The temperature distribution near the end of the atmospheric flight is shown in Fig. 18 which is made up of 4 frames: the trajectory point (top-right corner), the overall launcher (middle), planar fins (top-left corner) and base plate/nozzles cluster (bottom-left corner). For every frame, a suitable contour scale is used.

The highest temperature occurs on the leading edge of the planar fin, close to the tip, with a peak of $1500 \mathrm{~K}$. Concerning the base plate, high temperatures are reached in the area enclosed by the engines cluster especially along $Y$-axis. The external surfaces of the nozzles which are not operational during the retro-burn experience peak temperatures of $800 \mathrm{~K}$ close to the nozzle exit. The central body, from the top up to the folded legs, is characterized by an average temperature
Table 1 Material properties used for the exemplary lumped-mass thermal analysis

\begin{tabular}{llll}
\hline Surface emissivity & $\varepsilon$ & 0.2 & $(-)$ \\
Wall thickness & $\delta$ & 5 & $(\mathrm{~mm})$ \\
Density & $\rho$ & 2600 & $\left(\mathrm{Kg} / \mathrm{m}^{3}\right)$ \\
Heat capacity & $c$ & 900 & $(\mathrm{~J} / \mathrm{Kg} / \mathrm{K})$ \\
\hline
\end{tabular}

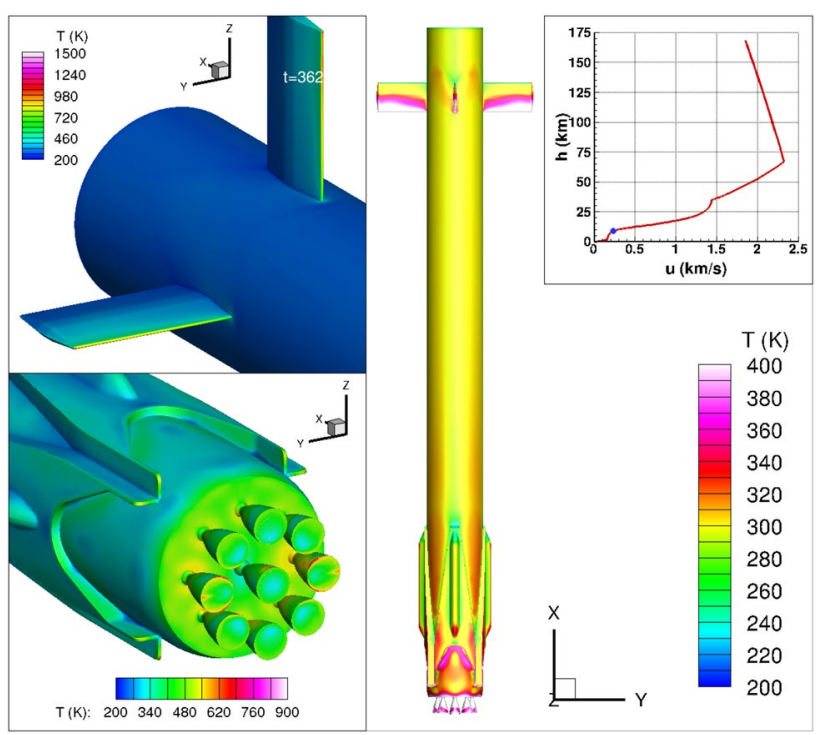

Fig. 18 ATDB application - RETALT1 surface temperature distribution

of $300 \mathrm{~K}$, higher values can be found in the final part of the launcher.

\section{Conclusion}

A fast-response surrogate model for the aero-thermodynamic heating of the RETALT1 launcher, during both the ascent flight and the atmospheric entry, has been created. This model is based on an aero-thermal database (ATDB) consisting in a large set of steady-state CFD results for the surface heat fluxes for different flight regimes and surface temperatures. Interpolation algorithms allow the estimation of heat loads as a function of the flight time and local surface temperatures. The computational matrix covered the entire RETALT1 flight trajectory. CFD simulations were performed mainly around peak heating and at critical flight conditions, whereas scaling laws are used to evaluate thermal loads in flight conditions characterized by low heating rates.

Representative flow field solutions were analysed in detail, and typical phenomena were highlighted. During the ascent phase, it is possible to distinguish two different 
flow modes: low altitude and high altitude. Low altitudes are characterized by a large atmospheric ambient pressure, the exhaust plumes are confined and the intensities of plume-plume interactions on the launcher base plate are limited, resulting in relatively low heat fluxes. At higher altitudes, the ambient pressure is lower and the plumes significantly spread out resulting in strong plume-plume interaction. The thermal loads on the base plate are significantly higher and the heating pattern is closely related to the recirculation regions which redirect the hot exhaust gases towards the surface.

These flow modes can also be recognized during the entry flight. Presented results show that retro-burns tend to protect the base area of the launcher from excessive heat loads whereas the hot exhaust gases may cause significant leadingedge heating at surface protrusions and control surfaces. The flow field conditions at the end of the retro-burn provide the most critical thermal load on the leading edge of the planar fin. The heat flux predictions during the retro-burn maneuver are subject to large uncertainties. This is primarily due to the impact of RANS turbulence modelling. Further work is required to assess and qualify standard RANS models for these flows.

During the aerodynamic phase following the retro-burn, the absence of a shielding retro plume, combined with the higher density due to the lower altitude and the flow velocity directed towards the base structure leads to high heat fluxes in the base area.

The turbulence modelling sensitivity analysis highlighted considerable changes on the external flow field structure depending on the turbulence model used. Major differences can be observed also in the heat flux pattern on the lower part of the vehicle. This significant modelling uncertainty requires additional assessment and validation. Therefore, several ground test campaigns are planned within the RETALT project to address this issue. The resulting data are expected to contribute to the empirical knowledge about the applicability of RANS turbulence models for the present flow phenomena.

Finally, the ATDB has been successfully coupled with a simple structural response model to compute the temperature history on RETALT1 surface.

At the current state-of-the-art, the ATDB represents a valuable tool for the preliminary evaluation of the thermal loads occurring on the launcher surface and the identification of critical flow conditions. Accurate load evaluations in a technical design process require a reduction of prediction uncertainties which are predominantly caused by turbulence modelling assumptions.

Acknowledgements This project has received funding from the European Union's Horizon 2020 research and innovation framework program under grant agreement No 821890 . We gratefully acknowledge the interest in our work and the opportunity to forward this essential research.

Funding Open Access funding enabled and organized by Projekt DEAL.

Open Access This article is licensed under a Creative Commons Attribution 4.0 International License, which permits use, sharing, adaptation, distribution and reproduction in any medium or format, as long as you give appropriate credit to the original author(s) and the source, provide a link to the Creative Commons licence, and indicate if changes were made. The images or other third party material in this article are included in the article's Creative Commons licence, unless indicated otherwise in a credit line to the material. If material is not included in the article's Creative Commons licence and your intended use is not permitted by statutory regulation or exceeds the permitted use, you will need to obtain permission directly from the copyright holder. To view a copy of this licence, visit http://creativecommons.org/licenses/by/4.0/.

\section{References}

1. Botelho, A., Martinez, M., Recupero, C., Fabrizi, A., Zaiacomo, G.D.: Design of the return gnc solution for the retro-propulsive vertical landing of retalt. CEAS Space Journal (Under Review)

2. Bottin, B.: Aerothermodynamic model of an inductively-coupled plasma wind tunnel. University of Liege, PhD-Thesis (1999)

3. Chapman, G.: Theoretical laminar convective heat transfer and boundary layer characteristics on cones at speeds to $24 \mathrm{~km} / \mathrm{s}$. NASA TN D-2463 (1964)

4. Ecker, T., Karl, S., Dumont, E., Stappert, S., Krause, D.: Numerical study on the thermal loads during a supersonic rocket retropropulsion maneuver. J. Spacecr. Rockets 57(1), 131-146 (2020)

5. Fetcher, S., Karl, S., Hannemann, V., Hannemann, K.: Simulation of lox/gh2 single coaxial injector at high pressure conditions. AIAA/SAE/ASEE Joint Propulsion Conference, AIAA Propulsion and Energy Forum, 10.-12. Juli 2017, Atlanta

6. Gerlinger, P.: An implicit multigrid method for turbulent combustion. J. Comput. Phys. 167, 247-276 (2001)

7. Gordon, S., McBride, B.J.: Computer program for calculation of complex chemical equilibrium compositions and applications. NASA Reference Publication 1311, New York (1994)

8. Karl, S.: Numerical investigation of a generic scramjet engine. PhD-Thesis, TU-Dresden, URL: https://nbn-resolving.org/ urn:nbn:de:bsz:14-qucosa-68695 (2011)

9. Koelle, D., Kuczera, H.: Sänger ii, an advanced launcher system for europe. Acta Astronautica 19(1), 63-72 (1989)

10. Langer, S., Schwöppe, S., Kroll, N.: The dlr flow solver tau-status and recent algorithmic developments. AIAA Paper 2014-0080 (2014)

11. Marwege, A., Gülhan, A., Klevanski, J., Riehmer, J., Kirchheck, D., Karl, S., Bonetti, D., Vos, J., Jevons, M., Krammer, A., Carvalho, J.: Retro propulsion assisted landing technologies (retalt): Current status and outlook of the eu funded project on reusable launch vehicles. 70th International Astronautical Congress (IAC), Washington D.C., United States (2019)

12. Menter, F.R.: Two-equation eddy-viscosity turbulence models for engineering applications. AIAA J. 32(8), 1598-1605 (1994). https://doi.org/10.2514/3.12149

13. Spalart, P., Allmaras, S.: A one-equation turbulence model for aerodynamic flows. AIAA Paper 1992-0439 (1992)

14. Sutton, K., Graves, R.: A general stagnation point convective heating equation for arbitrary gas mixtures. NASA TR-R-376 (1971) 
15. Wilcox, D.C.: Reassessment of the scale-determining equation for advanced turbulence models. AIAA J. 26(11), 1299-1310 (1994). https://doi.org/10.2514/3.10041
Publisher's Note Springer Nature remains neutral with regard to jurisdictional claims in published maps and institutional affiliations. 